\title{
General practice residency training and the osteopathic profession: Trends and issues for the 1990s
}

\author{
ANTHONY D. AQUILINA, DO
}

With the 1989-1990 training year, the length of postinternship residency training in osteopathic general practice will increase from 1 to 2 years. The longer residency is expected to give trainees a more complete and more competitive education and to protect them against discrimination regarding hospital privileges. With this change comes the opportunity to evaluate the current status of residency training in the field and to use the data as the basis for making rational predictions and recommendations for the future of the specialty.

The author considers the effect of curriculum changes on the operation of training residents in osteopathic general practice. He examines the structure of the new training program and discusses issues pertaining to osteopathic general practice.

The character of residency training in osteopathic general practice is in a state of flux. The American Osteopathic Association (AOA) and the American College of General Practitioners in Osteopathic Medicine and Surgery (ACGP) have extended the postinternship resi-

Dr. Aquilina is an assistant professor, family practice department, of the Philadelphia College of Osteopathic Medicine, where he also serves as outreach coordinator for the general practice residency program.

Reprint requests to Anthony D. Aquilina, DO, department of family practice, 4190 City Ave, 4th Floor, Rowland Hall, Philadelphia, PA 19131. dency to a mandatory 2 years, starting with those entering the residency in July $1989 .{ }^{1}$ The purposes of this mandate are to offer residents the most complete training experience possible and-while still maintaining the distinctiveness of osteopathic medicine-to provide them with credentials that will be equivalent to those obtained in allopathic programs.

Allopathic programs are in significant competition for residents. In 1987, 551 DOs were in allopathic family medicine programs,${ }^{2}$ compared with 243 in AOA-approved spots. ${ }^{3}$ The 551 number includes residents in all 3 years of training, while the 243 number includes, for the most part, those in the 1 postinternship year, the small exception being those doing a voluntary second year. However, the 1987 figure represents a $72 \%$ increase over that of 1985 , when the number of osteopathic physicians in allopathic family medicine training was $318^{2}$ (Table 1 ).

Obviously, a high percentage of residents are attracted to allopathic programs. The reasons given by local residents for deciding to pursue allopathic education include the belief that 3 years of postgraduate training are needed for competency in family practice and the fear that osteopathic training per se or any training of less than 3 years will restrict their privileges or future job opportunities.

A minority of the DOs in allopathic programs are there because they could not get into the osteopathic program they desired. At the University of Medicine and Dentistry of New 


\begin{tabular}{|lcc|}
\hline \multicolumn{1}{|c|}{$\begin{array}{c}\text { Table 1 } \\
\text { Osteopathic Residents in Primary Care Specialties } \\
\text { in Allopathic and Osteopathic Programs, 1987 }\end{array}$} \\
\hline Program & $\begin{array}{c}\text { No. of } \\
\text { osteopathic } \\
\text { residents }\end{array}$ & $\begin{array}{c}\text { No. of } \\
\text { allopathic } \\
\text { residents }\end{array}$ \\
\hline $\begin{array}{l}\text { Family medicine/ } \\
\text { general practice }\end{array}$ & 243 & 551 \\
Pediatrics & 25 & 127 \\
Internal medicine & 255 & 431 \\
Obstetrics/gynecology & 109 & 97 \\
\hline
\end{tabular}

Jersey-School of Osteopathic Medicine, a 2year postinternship program has essentially been in place since 1981. It is currently a much sought-after residency and one that has confirmed the expectation that the added year would protect the resident against hospital discrimination. With these data in mind, we can attempt to look at the current status of residency training in general practice, the content and emphasis of osteopathic programs, the way they compare with allopathic programs, and the possible future effects of current medical trends on osteopathic residency training.

\section{Ambulatory and longitudinal care}

For many reasons, the direction of emphasis in medical care shifted in the 1980 s. No longer is the hospital the definitive therapeutic locale. Ambulatory service has become a legitimate source of complete medical care. Family practitioners spend a minimum of $75 \%$ of their time in the office setting. Less than $25 \%$ of their day involves hospital or other institutional care. We must therefore provide time in a general practice residency for experience in ambulatory decision making. The problems in doing so are: How should that experience be implemented, who should oversee it, and how should it be financed?

In traditional residency programs, rotational models are used that include rotations in "clinic" or outpatient care. For the given length of the rotation, the resident spends all day, every day, in the clinic; when the rota- tion is completed, he or she goes on to the next assignment, leaving the care of all patients to the next resident in clinic. Over the past several years, there has been some feeling that this system short-changes the resident in terms of continuity of care and responsibility for the long-term care of given patients. Thus, currently, the prevailing trend is toward longitudinal care, with a change in the model training site. In this type of program, the resident consistently spends several half-days per week throughout the year in an outpatient siteideally, developing a continuous patient base.

This concept of longitudinal care makes sense, and it is well thought of in government funding circles. Experience with this model in the program at the Philadelphia College of Osteopathic Medicine (PCOM) and in other institutions, however, has revealed some problems. In an excellent study conducted by Ellsbury and colleagues ${ }^{4}$ at the University of Washington School of Medicine, six training sites were evaluated. First, an attempt was made to define the content of the model teaching unit as compared with the content of a private medical practice and, second, to decide to what degree continuity of care in the resident-patient relationships was achieved. The researchers found that practice at the model sites differed significantly from that of private practice. Specifically, the residents saw a disproportionately high number of acute problems, such as respiratory tract infections, otitis media, conditions requiring general medi- 
cal examinations, and a comparatively low number of long-term follow-up examinations, such as those for hypertension, osteoarthritis, diabetes mellitus, and coronary artery disease. This, of course, runs contrary to the concept of longitudinal training.

For continuity of care, the University of Washington researchers found that even in the most efficiently run programs, achieving a $50 \%$ continuity rate was considered a major success. They summated the continuity of care on the basis of arithmetic models first published in the American Journal of Public Health $^{5}$ in 1980 . The reasons for the difficulty in maintaining continuity of care include limited availability of the residents, insufficient time for developing resident-patient relationships, and instability of training-site patient populations.

Our experience at PCOM has been consistent with the findings of the University of Washington study, especially with regard to continuity of care. Our general practice residents are often frustrated by the difficulty of follow-up care. In some programs, the continuity problem is attacked by assigning each resident a caseload of established patients at the start of his or her residency, with the intention that these patients will be followed up throughout the training period and that new patients will be added with time. This, of course, requires an amenable training-site population.

The findings of studies such as that of the University of Washington need not suggest that the concept of longitudinal training is improper. For reasons stated previously, the concept is sound. What will probably evolve are some modifications. At the end of the 19891990 training year, we intend to use methods similar to those noted previously to evaluate our program for content and continuity of care. Depending on the results, we may refine the residency requirements to include a longitudinal experience in chronic care clinics. In addition, the pairing of residents with other residents or with attending physicians in careproviding teams may be one way to improve continuity of care in the longitudinal setting.

Some question exists as to who should su- pervise the residents and to what degree. The results of a study by Carey and Bennard ${ }^{6}$ suggest that the best supervision and the greatest amount of interaction with the residents are offered by preceptors who are generalists rather than subspecialists and who are exclusively available for training purposes rather than available on an "as needed" basis. This type of preceptor was found to supply immediate teaching reinforcement and to decrease the risk of potentially litigious errors by residents. As trainees progress from internship to secondand third-year postgraduate training, their ability and confidence grow, and their need for supervision decreases. As they develop more independence, residents consult preceptors and subspecialists less frequently.

The last issue in ambulatory training has to do with the financial burden of training. As government pass-through support to training hospitals becomes threatened by budget constraints, institutions are looking closely at which and how many house-staff physicians it benefits them to keep. Superficially, considering that an intern cost a hospital a minimum of $\$ 15,000$ in $1977,{ }^{7}$ many administrators would not find it cost-effective to support an ambulatory-based resident. As for primary care residents, even medical educators such as Perkoff ${ }^{8}$ of the University of Missouri concede that resident-oriented departments cover no greater than one third of their expenses with income derived from providing care. However, Perkoff does state that at his institution and elsewhere, the family medicine department generates for specialists an income from referrals equal to that generated for itself; and for its base hospital, five times as much. In fact, a primary care physician produces an inpatient revenue that is approximately equal to the overall average of that produced by all specialists. ${ }^{9}$ Considering the large number of primary care physicians per hospital, the total funds generated by this group are undeniably critical to the stability of a hospital. Thus, hospitals may be open to providing more financial support to their general practice programs.

Perkoff suggests that one way to subsidize primary care in a medical school is through interdepartmental funding: "What I am pro- 
Table 2

Ambulatory Care: Problems and Proposed Solutions

\begin{tabular}{|c|c|}
\hline Problem & Proposed solution \\
\hline $\begin{array}{l}\text { Need to promote resident } \\
\text { responsibility for long-term } \\
\text { continuity of care }\end{array}$ & $\begin{array}{l}\text { Longitudinal care in } \\
\text { ambulatory care sites }\end{array}$ \\
\hline $\begin{array}{l}\text { Content of care in ambulatory } \\
\text { care sites }\end{array}$ & $\begin{array}{l}\text { Establish chronic disease } \\
\text { clinics, eg, hypertension } \\
\text { clinics, arthritis clinics, etc }\end{array}$ \\
\hline $\begin{array}{l}\text { Maintenance of continuity of } \\
\text { care }\end{array}$ & $\begin{array}{l}\text { Resident-resident or resident- } \\
\text { attending teams in } \\
\text { longitudinal care sites }\end{array}$ \\
\hline $\begin{array}{l}\text { Providing complete outpatient } \\
\text { experiences }\end{array}$ & $\begin{array}{l}\text { Adding a short-term, full-time } \\
\text { outpatient primary care } \\
\text { rotation }\end{array}$ \\
\hline - Providing adequate supervision & $\begin{array}{l}\text { Having attendings exclusively } \\
\text { available for consultation }\end{array}$ \\
\hline - Need to promote independence & $\begin{array}{l}\text { Recognition by preceptors that } \\
\text { upper-level residents need } \\
\text { appropriate decision-making } \\
\text { freedom }\end{array}$ \\
\hline - Funding & $\begin{array}{l}\text { Continued hospital/medical } \\
\text { school support; interdepart- } \\
\text { mental funding }\end{array}$ \\
\hline
\end{tabular}

posing is that clinical income in medical schools be regarded ... as income to the schools rather than to their departments. . . this means using the income from services provided by specialty departments to finance the reorganization of care in systems in which primary care would be the central function of a school's medical system"8 (Table 2). This is especially apropos for osteopathic medical institutions, whose basic philosophy is founded on primary care.

\section{Hospital medicine and critical care}

Despite the trend toward ambulatory care, hospital medicine remains an integral part of family practice, and residents are still entitled to comprehensive inpatient medical training. The ACGP and AOA assume that the emphasis of the rotating internship ${ }^{1}$ should continue to be on hospital training, which will provide a foundation for the following 2-year residency. Inpatient training in the residency consists of rotations in internal medicine subspecialties and care of general practice patients from the ambulatory training sites. ${ }^{10}$

The findings of a study on recent residency graduates from a family medicine program in Maryland showed that $97 \%$ of the graduates had received hospital privileges in medicine; and 87 , in critical care units. ${ }^{11}$ These numbers may be uncharacteristically high for some regions, but they do show the importance of hospital medicine in a resident's training. Hospital privilege conflicts sometimes occur, most often because of speciality control over privilege boards ${ }^{12}$ Scientific studies, however, have consistently shown that the quality of care given by general practitioners is good. ${ }^{13} \mathrm{An}$ ecdotal accounts of the poor care given by some general practitioners represent either isolated problems relating to a particular physician or prejudicial bias on the part of the storyteller; it is certainly not reasonable to categorically restrict privileges to family practitioners on the basis of such accounts. At PCOM, we sup- 
port a strong inpatient service, and our residents are trained to confidently take responsibility for hospitalized patients. If a general practice resident plans to practice in an area where necessity mandates that he or she have more critical care experience, he or she can use the elective time to achieve that level of competence.

\section{Obstetrics and pediatrics}

Obstetric care in the United States differs by region. For example, in the industrial Northeast, it is very unusual for family physicians to provide obstetric care; but in the Midwest, family physicians are more likely to do deliveries than not-and in fact do so with respectable outcomes. ${ }^{14}$ They supply a needed service in rural areas, where the availability of obstetricians is limited.

Probably the single most important reason that family practitioners have left the obstetric business is the monumental malpractice risks. With lawsuits commonplace with any poor outcome and with malpractice premiums soaring beyond the potential increased income, most family practitioners in populated areas have abandoned this service.

In the Northeast region of the United States, osteopathic residency programs are shying away from obstetric training in favor of outpatient gynecology, an area of general practice that is enjoying steady growth. The development of the 2-year postinternship program, however, allows us the opportunity to manipulate schedules to provide 4 months of obstetric training to the minority of residents desiring it. Some scholars suggest that given the complexity of current obstetric therapeutics, even this represents an inadequate amount of time. They suggest an extra year of training for residents who are interested in providing obstetric care in practice.

In contrast, pediatrics represents a strong part of most family practices. Family physicians see $47 \%$ of all patients aged 15 to 19 years old, $41 \%$ of those aged 10 to 14 , and $31 \%$ of those aged 5 to 9 . In the same age groups, pediatricians see $6 \%, 26 \%$, and $43 \%$, respectively. Nineteen percent of all the patients of family physicians are under 17 years of age. ${ }^{15}$
Clearly, family physicians provide the bulk of pediatric care to the United States' young, especially its adolescents.

It follows, then, that it is essential to train residents thoroughly in all aspects of pediatric care. Ambulatory pediatrics can be emphasized, but neonatal services and inpatient management of common pediatric dilemmas should not be excluded. In addition, residents planning to do a lot of pediatrics in practice should be encouraged to use elective time to further sharpen their skills, especially in pediatric emergency medicine. Ambulatory pediatrics could be incorporated into the model ambulatory care clinic. Often institutions with residencies in both pediatrics and general practice compete for both patients and trainers. The ambulatory care site could serve as a vehicle for cooperation between pediatric and general practice residents in the care of the pediatric population.

\section{Geriatrics}

The AOA, in association with the ACGP and the American College of Osteopathic Internists, offers a 2-year subspecialty program in geriatric medicine-defined as care given to elderly patients ( 62 years or older) by general practitioners or internists. This 2-year program gives the resident the opportunity to qualify for an additional certificate in geriatric medicine. Participants must first complete 2 to 3 years of postgraduate training in their primary residencies. Geriatric rotations are not a required component of the osteopathic general practice residency program, inasmuch as training in geriatric medicine is presumably received throughout the training years. In some programs, including our own, a fellowshiptrained geriatrician is engaged to directly train residents in this specialty.

Undeniably, the science of geriatrics needs to be taught to any physician entering family practice, especially considering the growing percentage of the US population over the age of 65 . The question arises, then, to what degree geriatric medicine should be taught as a subspecialty instead of as a natural part of the flow of family practice.

A 2-year fellowship in geriatrics will help 
a resident who is intending to enter an academic environment but is far less likely to benefit one entering private practice. ${ }^{16}$ In fact, to the latter, the 2 years away from the nongeriatric aspects of primary care may be detrimental. The role of the geriatric specialist may thus be confined to academia, research, or to patient care in large distinct geriatric centers. As the AOA states, "Care of the geriatric patient is the normal extension of the general practitioner's responsibility."1 Therefore, within their general practice training years, residents entering the practice of primary care medicine must develop competency in the physiologic, psychologic, and societal aspects of this fundamental science.

\section{Behavioral medicine}

A consensus exists that behavioral science should be included in primary care training. How and to what degree remain key questions. In $1977, \mathrm{Kuhn}^{17}$ wrote of a "paradigm shift" of the role of medicine in the community. This shift has been from an emphasis on subspecialties to a "biopsychosocial understanding of a patient as a whole person." 18 This focus, at least theoretically, represents the foundation of osteopathic philosophy. Recently, governmental agencies involved in medical funding have shown a desire to promote this trend.

In a study sponsored by the National Institute of Mental Health, ${ }^{19}$ the question of how and to what degree mental health training took place in family practice and internal medicine residency training was examined. The findings showed that in traditional internal medicine programs, specific time blocks were rarely devoted to mental health rotations; instead, mental health education took the form of consultation from psychiatry services in which organic brain disorders were emphasized. In traditional internal medicine programs, an average of $\$ 1120$ per resident per year was spent on mental health training. In family practice programs, psychologists and other social scientists were used as teachers more often than psychiatrists were, mental health rotations were often offered, and life-cycle issues were emphasized more than organic diseases. In family practice programs, $\$ 4014$ per resident per year was spent on this training. Internal medicine programs identified as primary care internal medicine conformed more closely with family practice. Some degree of cost containment could be achieved if family practice and internal medicine programs in the same institution shared behavioral scientists.

An attempt has been made to determine what role patients see their physicians playing in behavioral science issues. ${ }^{20}$ The findings show great variability in patient desires and expectations. Few patients want the physician to be directly involved in problems related to direct work, religion, or financial matters. Most patients want the physician's help with psychologic or life-cycle problems. Often patients seek information from their physicians concerning situations such as family violence, behavioral problems, or drug problems but expect to be referred to appropriate agencies. All studies have suggested that patients might be more likely to consult physicians for guidance concerning psychosocial problems if the medical community promoted itself as a source of help (Table 3).

As well stated by Shapiro, ${ }^{18}$ "the goal of behavioral science training is to [help] residents learn how to assume empathetically some of the patient's sufferings and concerns, to distinguish between the voice of medicine and the voice of the real world, and to probe their own life histories, which inevitably color interactions with patients." For general practice residents, this training usually takes the form of a didactic lecture series and one-on-one or small-group clinical teaching.

A comprehensive lecture series for residents should be geared toward such issues as family dynamics; ethnic and religious attitudes toward medicine; ethical issues in medicine, death and grief; and physician well-being. A lecture series in which an attempt is made to reteach basic psychosociology without incorporating a medical foundation will fail from the residents' boredom. The clinical teaching involves an interaction between the behavioral scientist and the resident in the practice setting. Interviewing skills and counseling techniques are emphasized. In some programs, a physician plays the part of the patient in evalu- 


\section{HYPERTENSION IS USUALLY SILENT}

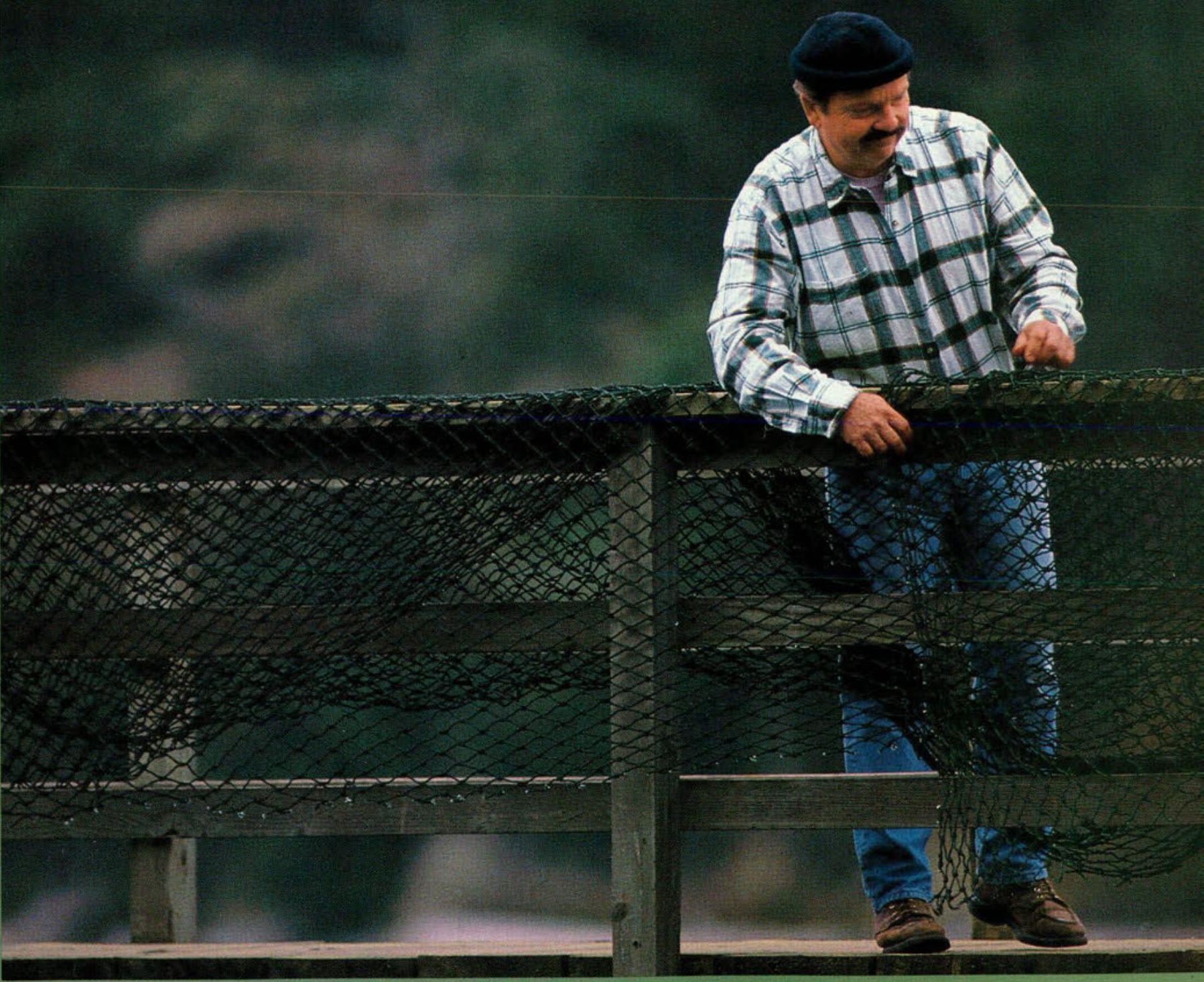



For many

hypertensive patients

\section{THERAPY THAT MAY BE AS SILENT AS HYPERTENSION ITSELF}

VASOTEC $^{\circledast}$ (Enalapril Maleate, MSD) is generally well tolerated and not characterized by certain undesirable effects associated with selected agents in other antihypertensive classes.

VASOTEC is contraindicated in patients who are

hypersensitive to this product and in patients with a history of angioedema related to previous treatment with an ACE inhibitor.

For a Brief Summary of Prescribing information, please see the last page of this advertisement.

Copyright $\odot 1989$ by Merck \& CO., INC. 

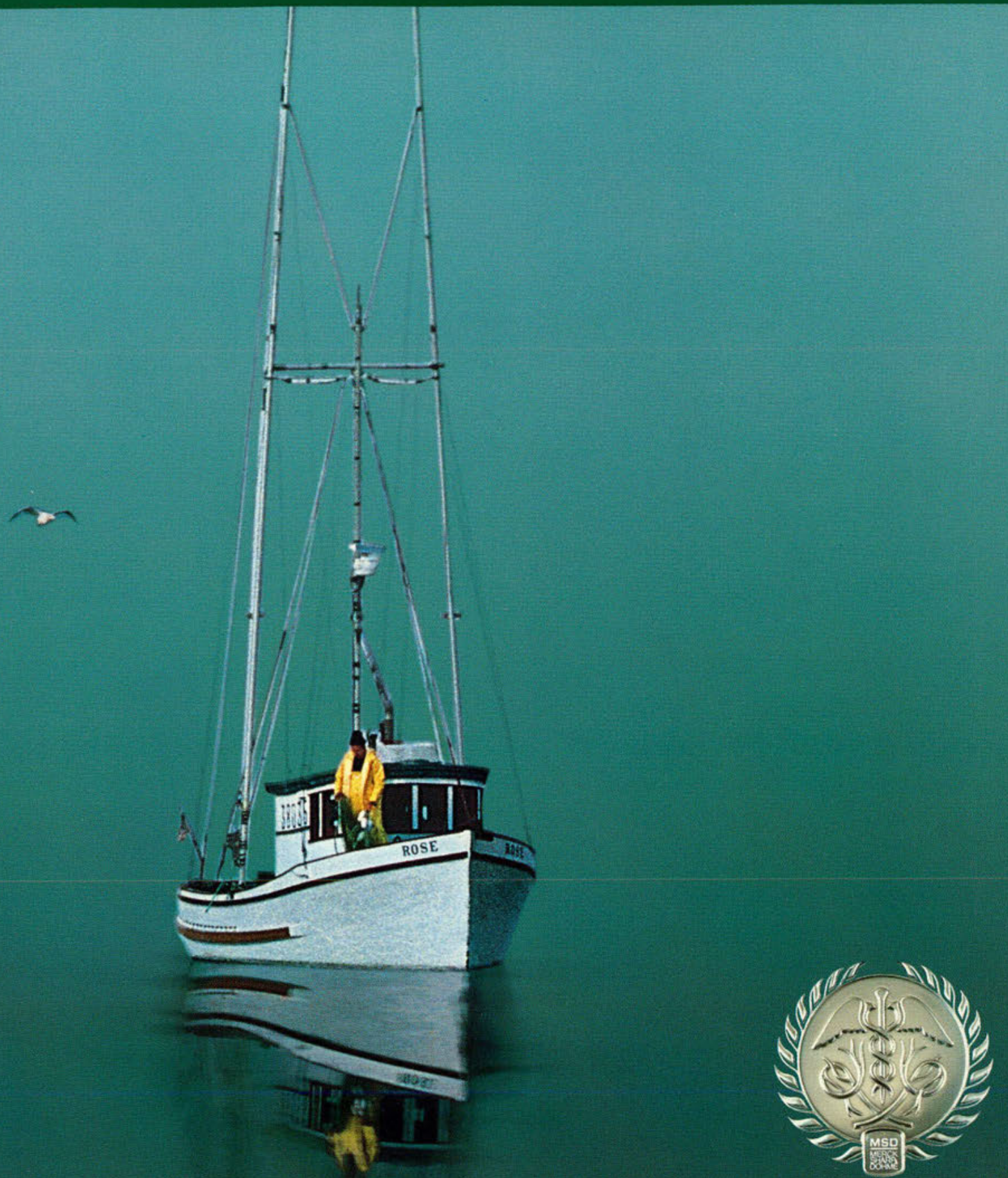

FOR MANY HYPERTENSIVE PATIENTS ONCE-A-DAY VASOTEC (ENALAPRIL MALEATE $\mid$ MSD) 



\section{VASOTEC (ENALAPRIL MALEATE $\mid$ MSD)}

VASOTEC is available in 2.5-mg, $5-\mathrm{mg}, 10-\mathrm{mg}$, and 20-mg tablet strengths.

Contraindications: VASOTEC (Enalapril Maleate, MSD) is contraindicated in patients who are hypersensitive to Whis product and in patients with a history of angioedema related to previous treatment with an ACE inhibitch. Warnings: Angioedema: Angioedema of the face, extremities, lips, tongue. glottis, and/or larynx has been reported in
patients lreated with ACE inhibitors, including VASOTEC. In Such cases. VASOTEC should be promptly discontinued patients Ireated with ACE inhibitors. including VASOTEC. In such cases, VASOTEC should be promptly discontinued
and the patient carefully observed until the swelling disappears. In instances where swelling has been confined to the tace and lips, the condition has generally resolved without treatment, although antihistamines have been useful in
relieving symptoms. Angioedema associated with laryngeal edema may be tatal. Where there is involvement of relieving symptoms. Angioedema associated with laryngeal edema may be tatal. Where there is involvement of
the tongue, glottis, or larynx likely to cause airway obstruction, appropriate therapy, e.g., subcutaneous
epinephrine solution 1:1000 ( $0.3 \mathrm{~mL}$ to $0.5 \mathrm{~mL})$, should be promptly administered. (See ADVERSE
REACTONS.)

Hypotension: Excessive hypotension is rare in uncomplicated hypertensive patients treated with VASOTEC alone.
Patients with heart tailure given VASOTEC commonly have some reduction in blood pressure, especially with the first Patients with heart failure given VASOTEC commonly have some reduction in blood pressure, especially with the first
dose, but discontinuation of therapy for continuing symplomatic hypotension usually is not necessary when dosing instructions are followed; caution should be observed when initiating therapy. (See DOSAGE AND ADMINISTRA.
TION.) Patients at risk for excessive hypotension, sometimes associaled with oliguria and/or progressive azotemia and rarely with acute renal tailure and/or death, include those with the following conditions or characteristics heart
and tailure, hyponatremia. high-dose diuretic therapy, recent intensive diuresis or increase in diuretic dose, renal dialysis, with heart tailure), reduce the diuretic dose, or increase salt intake cautiously betore initiating therapy with VASOIEC in patients at risk for excessive hypotension who are able to tolerate such adjustments. (See PRECAUTIONS . Drug Interactions and ADVERSE REACTIONS.) In patients at risk lor excessive hypotension, therapy should be started under
very close medical supervision and such patients should be followed closely for the first two weeks of treatment and whenever the dose of enalapril and/or diuretic is increased. Similar considerations may apply to patients with ischemic heart disease or cardiovascular disease in whom an excessive fall in blood pressure could result in a myocardial infarction or cerebrovascular accident. If excessive hypotension occurs, the patient should be placed in the supine
position and, if necessary, receive an intravenous infusion of normal saline. A transient hypotensive response is not a Contraindication to further doses of VASOTEC. Which usually can be given without difficulty once the blood pressure
has stabilized. If symptomatic hypotension develops. a dose reduction or discontinuation of VASOTEC or concomitant diuretic may be necessary.

Neutropenia/Agranulocytosis: Another ACE inhibitor, captopril, has been shown to cause agranulocytosis and bone marrow depression, rarely in uncomplicated patients but more frequently in patients with renal impairment. especially
if they also have a collagen vascular disease. Available data from clinical trials of enalapril are insufticient to show that enalapril does not cause agranulacytosis at similar rates. Foreign marketing experience has revealed several cases of neutropenia or agranulocylosis in which a causal relationship to enalapril cannot be excluded. Periodic monit
white blood cell counts in patients with collagen vascular disease and renal disease should be considered.

Precautions: General: Impaired Renal Function: As a consequence of inhibiting the renin-angiotensin-aldosterone system, changes in renal function may be anticipated in susceptible individuals. In patients with severe heart failure
whose renal function may depend on the activity of the renin-angiotensin-aldosterone system, treatment with ACE inhibitors, including VASOTEC, may be associated with oliguria and/or progressive azotemia and rarely with acute

In clinical studies in hypertensive patients with unilateral or bilateral renal artery stenosis. increases in blood urea nitrogen and serum creatinine were observed in $20 \%$ of patients. These increases were almost always reversible upon
discontinuation of enalapril and/or diuretic therapy. In such patients. renal function should be monitored during the
first few weeks of therapy.

Some patients with hypertension or heart failure with no apparent preexisting renal vascular disease have developed concomitantly with a diuretic. This is more likely to occur in patients with preexisting renal impairment. Dosage

Evaluation of patients with hypertension or heart failure should always include assessment of renal

Hyperkalemia: Elevated serum potassium ( $>5.7 \mathrm{mEq} / \mathrm{L}$ ) was observed in approximately $1 \%$ of hypertensive patients was a cause of discontinuation of therapy in $0.28 \%$ of hypertensive patients. In clinical trials in heart lailure, hyper-

Risk factors for the development of hyperkalemia include renal insufficiency, diabetes mellitus, and the concomitant use of potassium-sparing diuretics, potassium supplements, and/or potassium-containing salt substitutes, which

Surgery/Anesthesia: In patients undergoing major surgery or during anesthesia with agents that produce hypotension, enalapril may block angiotensin II formation secondary to compensatory renin release.
considered to be due to this mechanism, it can be corrected by volume expansion.

Information for Patients:

Angioedema: Angioedema, including laryngeal edema, may occur especially following the first dose of enalapriing of face, extremities, eyes, lips, tongue, difficulty in swallowing or breathing) and to take no more drug until they have consulted with the prescribing physician.

Hypotension: Patients should be cautioned to report lightheadedness. especially during the first tew days of therapy if actual syncope occurs, the patients should be told to discontinue the drug until they have consulted with the prescribing physician:

All patients should be cautioned that excessive perspiration and dehydration may lead to an excessive fall in blood pressure because of reduction in fluid volume. Other causes of volume depletion such as von
also lead to a fall in blood pressure: patients should be advised to consult with the physician.

Hyperkalemia: Patients should be told not to use salt substitutes containing potassium without consulting their

Neutropenia: Patients should be told to report promptly any indication of infection (e.g. sore throat, fever) which may

NOTE: As with many other drugs, certain advice to patients being treated with enalapril is warranted. This information s intended to aid in the sate and effective use of this medication. It is not a disclosure of all possible adverse Drug interactions.

Hypotension: Patients on Diuretic Therapy: Patients on diuretics and especially those in whom diuretic therapy was recently instituted may occasionally experience an excessive reduction of blood pressure after initiation of therapy with enalapril. The possibility of hypotensive effects with enalapril can be minimized by either discontinuing the
diuretic or increasing the salt intake prior to initiation of treatment with enalapril. If it is necessary to continue the diuretic or increasing the salt intake prior to initiation of treatment with enalapril. If it is necessary to continue the
diuretic, provide close medical supervision after the initial dose for at least two hours and until blood pressure has diuretic, provide close medical supervision after the initial dose for at least two hours and until b
stabilized for at least an additional hour. (See WARNINGS and DOSAGE AND ADMINISTRATION.)

Agents Causing Renin Release: The antihypertensive effect of VASOTEC is augmented by antihypertensive agents that cause renin release (e.g. diuretics). Other Cardiovascular Agents: VASOTEC has been used concomitantly with beta-adrenergic-blocking agents, methyl
dopa, nitrates, calcium-blocking agents, hydralazine. prazosin, and digoxin without evidence of clinically significan adverse interactions.

Agents Increasing Serum Potassium: VASOTEC attenuates potassium loss caused by thiazide-type diuretic Potassium-sparing diuretics (e.g., spironolactone, triamterene, or amiloride), polassium supplements, o tant use of these agents is indicated because of demonstrated hypokalemia. they should be used with caution an
with frequent monitoring of serum potassium. Potassium-sparing agents should generally not be used in patients with heart tailure receiving VASOTEC

Lithium: Lithium toxicity has been reported in patients receiving lithium concomitantly with drugs which cause elim ination of sodium, including ACE inhibitors. A tew cases of lithium toxicity have been reported in patients receivin serum lithium levels be monitored trequently if enalapril is administered concomilantly with lithium.

Pregnancy - Category C: There was no tetotoxicity or teratogenicity in rats treated with up to $200 \mathrm{mg} / \mathrm{kg} / \mathrm{day}$ of enalapp in rats given $1200 \mathrm{mg} / \mathrm{kg} /$ day of enalapril but did not occur when these animals were supplemented with saline Enalapril was not teratogenic in rabbits. However, maternal and fetal toxicity occurred in some rabbits at doses o $\mathrm{kg} /$ day, but not at $30 \mathrm{mg} / \mathrm{kg} / \mathrm{day}$ ( 50 times the maximum human dose)

Radioactivity was found to cross the placenta following administration of labeled enalapril to pregnant hamsters

There are no adequate and well-controlled studies of ena april in pregnant women. However, data are availabie that
Show enalapril crosses the human placenta. Because the risk of tetal toxicity with the use of ACE inhibitors has not efit justifies the potential risk to the fetus

Postmarketing experience with all ACE inhibitors thus far suggests the following with regard to pregnancy outcome Fetal exposure during the second and third trimesters of pregnancy has been associated with fetal and neonatal mor.

When ACE inhibitors are used during the later stages of pregnancy, there have been reports of hypotension and senting decreased renal function in the fetus Infants exposed in utero to ACE inhibitors should be closely obserwed for hypotension. oliguria, and hyperkalemia If oliguria occurs, attention should be directed toward support of blood pressure and renal perfusion wifh the administration of fluids and pressors as appropriate. Problems associated with prematurity such as patent ductus arteriosus have occurred in association with maternal use of ACE inhibitors, but Nursing Mothers: Milk in lactating rats contains radioactivity following administration of ${ }^{2} \mathrm{C}$ enalapril maleate. It is nou nown whether this drug is secreted in human milk. Because many drugs are secreted in human milk. caution should Pediatric Use: Satety and effectiveness in children have not been established

Adverse Reactions: VASOTEC has been evaluated for safety in more than 10,000 patients. including over 1000
patients treated for one year or more. VASOTEC has been found to be generally well folerated in controlled clinica patients trealed for one year or

HYPERTENSION: The most trequent clinical adverse experiences in controlled trials were: headache $(5.2 \%)$. dizziness

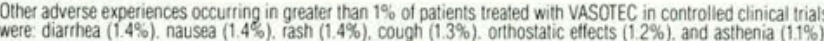
HEARI FAILURE: The most frequent clinical adverse experiences in both controlled and uncontrolled trials were; dizzidiarthea $(2.1 \%)$

Oher adverse experiences occurring in greater than $1 \%$ of patients treated with VASOTEC in both controlled and

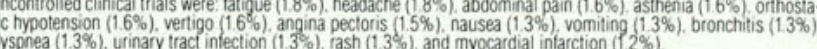
Other serious clinical adverse experiences occurring since the drug was marketed or adverse experiences occurring
in $0.5 \%$ to $1 \%$ of patients with hypertension or heart lailure in clinical trials in order of decreasing severity within each category:

Cardiovascular: Cardiac arrest. myocardial infarction or cerebrovascular accident. possibly secondary to excessiv hypotension in high-risk patients (see WARNNINGS.

Digestive: lleus. pancreatitis, hepatitis or cholestatic jaundice. melena anorexia, dyspepsia. constipation, glossitis, Musculoskeletal: Muscle cramps

Nervous/Psychiatric: Depression, confusion, ataxia, somnolence, insomnia. nervousness, paresthesia

Urogenilal: Renal tailure, oliguria, renal dysfunction (see PRECAUTIONS and DOSAGE AND ADMINISTRATION) Respiratory Bronchospasm, ihinorrhea sore throat and hoarseness, asthma upper respiratory intection.

Skin: Herpes zoster, urticaria. pruritus, alopecia. flushing. hyperhidrosis

Specia/ Senses: Blurred vision, taste alteration, tinnitus.

A symptom complex has been reported which, may include a positive ANA an elevated erythrocyle sedimentation rate. dermatologic manifestations.

Angioedema: Angioedema has been reported in patients receiving VASOTEC $(02 \%)$. Angioedema associated with laryngeal edema may be fatal. If angioedema of the face. extremities, lips. longue. glottis, and/or larynx occurs. treat-
ment with VASOTEC should be discontinued and appropriate therapy instituted immediately. (See WARNiNGS. Hypotension: In the hypertensive patients. hypotension occurred in $0.9 \%$ and syncope occurred in $0.5 \%$ of patients $22 \%$ of patients. Hypotension or syncope was a cause for discontinuation of therapy in $1.9 \%$ of patients with heart lailure. (See WARNINGS.)

Clinical Laboratory Test Findings:

Serum Electrolytes: Hyperkalemia (see PRECAUTIONS), hyponatremis

Creatinine, Blood Urea Nitrogen: In controlled clinical trials, minor increases in blood urea nitrogen and serum creatinine. reversible upon discontinuation of therapy, were observed in about $0.2 \%$ of patients with essential hypertenpatients with renal artery stenosis. (See PRECAUTIONS.) In patients with heart failure who were aiso receiving continuation of VASOTEC and/or other concomitant diuretic therapy. were observed in about $11 \%$ of patients creases in blood urea nitrogen or creatinine were a cause for discontinuation in $12 \%$ of patients.

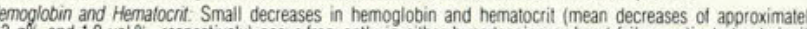
VASOTEC but are rarely of clinical importance unless another cause of anemia coexists. In clinical trials. less than $1 \%$ of patients discontinued therapy due to anemia

Other (Causal Relationship Unknown): In marketing experience. rare cases of neutropenia. thrombocytopenia, and deficiency.

Liver Function Tests: Elevations of liver enzymes and/or serum bilirubin have occurred

Dosage and Administration: Hypertension: In patients who are currently being treated with a diuretic, symptomatic continued for two to three days betore beginning therapy with VASOTEC to reduce the likelinood of hypotension (See WARNINGS.) if the patient's blood pressure is not controlled with VASOTEC alone, diuretic therapy may be resumed the diuretic cannot be discontinued. an initial dose of $2.5 \mathrm{mg}$ should be used under medical supervision for at least IONS. Drug interactions)

The recommended initial dose in patients not on diuretics is $5 \mathrm{mg}$ once a day. Dosage should be adjusted according to blood pressure response. The usual dosage range is $101040 \mathrm{mg}$ per day administered in a single dose or in two dosing interval. In such patients. an increase in dosage or twice-daily administration should be considered. If blood pressure is not controlled with VASOTEC alone. a diuretic may be added

Concomitant administration of VASOTEC with potassium supplements. potassium salt substitutes. or potassiumsparing diuretics may lead to increases of serum potassium (see PRECAUUTIONS)

Dosage Adjustment in Hypertensive Patients with Renal Impaiment: The usual dose of enalapril is recommended for patients with a creatinine clearance $>30 \mathrm{~mL} / \mathrm{min}$ (serum creatinine of up to approximately $3 \mathrm{mg} / \mathrm{dL}$ L). For patients may be fitrated upward until blood pressure is controlled or to a maximum of $40 \mathrm{mg}$ daily.

Heart Failure: VASOTEC is indicated as adjunctive therapy with diuretics and digitalis. The recommended starting supervision for at least wo hours and until blood pressure has stabilized for at least an additional hour. (See WARNINGS and PRECAUTIONS, Drug interactions.) If possible, the dose of the diuretic should be reduced, which may diminish the likelihood of hypotension. The appearance of hypotension after the initial dose of VASOTEC does not

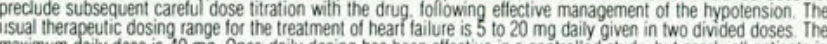
maximum daily dose is $40 \mathrm{mg}$. Once-daily dosing has been effective in a controlled study, but nearly all patients in this study were given $40 \mathrm{mg}$. the maximum recommended daily dose. and there has been much more experience with Weve-daily dosing. In addition, in a placebo-controlied study which demonstrated reduced mortality in patients with

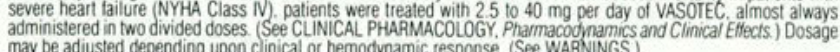

Dosage Adjustment in Patients with Heart Failure and Renal Impairment or Hyponatremia: in patients with heart failure $30 \mathrm{mE} / \mathrm{L}$ ) or with serum creatinine $>1.6 \mathrm{mg} / \mathrm{d}$ L. therapy should be initiated at $25 \mathrm{mg}$ daily under close medical supervision. (See DOSAGE AND ADMINISTRATION. Hear? bid, ithen $5 \mathrm{mg}$ bi.d. and higher as needed, usually at intervals of tour days or more, if at the time of dosage adjustment there is not excessin. The maximum daily dose is $40 \mathrm{mg}$

MSD

For more detailed information consult your MSD Representative or see Prescribing Information. Merck

MERCK 
Table 3

Patient Expectations of Family Physicians: Psychosocial Issues

\begin{tabular}{ll|}
\hline Issues & Patient expectations \\
\hline $\begin{array}{l}\text { Life-cycle problems: adjusting to } \\
\text { new baby, deaiing with death of } \\
\text { family member }\end{array}$ \\
- Psychologic problems: \\
depression, anxiety \\
- Alcohol/drug abuse \\
- Dealing with long-term pain \\
Coping with long-term illness \\
- Alcohol/drug abuse \\
- -
\end{tabular}

ating a resident's interviewing skills. In others, patient interview sessions are videotaped, with the consent of cooperative patients. At Michigan State University-College of Osteopathic Medicine, the family medicine department introduces a clinical behavioral science course to first-year medical students in an attempt to foster good interviewing and communication habits early in their education. ${ }^{21}$

\section{Preventive medicine}

Preventive medicine encompasses health promotion, risk modifications, and detection of asymptomatic disease. The American College of Physicians has set standards for preventive health techniques ${ }^{22}$ that should form an integral part of family practice. It has been consistently found, however, that both physicians in practice and those in residency training underuse preventive techniques. ${ }^{23}$

Several studies have been conducted to evalu- ate the effect of interventions that were believed to promote preventive medical practices on the part of residents. The findings have varied and do not consistently show that attempts to encourage preventive medicine are effective. Lectures, seminars, chart audits, and peer review do not seem to be as successful as simply putting in all patient charts an insert outlining preventive techniques and serving the physician as a reminder at the time of the office visit.

Among the areas of particular importance that should be promoted in residency training are cancer screening, smoking cessation, and diet and nutrition counseling. The American Cancer Society (ACS) has published guidelines for primary care screening for cancers that can be detected early. ${ }^{24}$ These guidelines deal with everything from the frequency of Pap smears to the use of mammography and flexible sigmoidoscopy for early cancer detection. The 
ACS recommendations are updated periodically and should be used as part of the routine health checkup (Table 4).

Family physicians can significantly affect our nation's health by encouraging their patients to stop smoking. In the United States, one out of every four deaths is caused by smoking tobacco. ${ }^{25}$ Smoking is easily assessed, yet it is frequently ignored by physicians. They often feel that their efforts to encourage their patients to stop smoking are fruitless because the patients refuse to listen. According to the 1979 Surgeon General's report, ${ }^{26}$ however, an estimated $10 \%$ to $25 \%$ of the smokers who were advised by their physicians to quit either did quit or smoked less. Successful techniques for encouraging patients to stop smoking have been published,$^{27}$ and the development of nicotine chewing gum has increased the ability of the physician to help patients cease smoking.

The recognition of the role of diet in health promotion and disease modification has led to a renewed interest in nutrition as a medical modality. Although historically knowledge of clinical nutrition has been neglected by teaching physicians, the importance of nutrition is well recognized, and the subject must be included in residency training. Other preventive medicine modalities include counseling in alcohol and substance abuse, exercise, birth control, and safe sexual practices.

\section{Osteopathic principles and practice}

The art of osteopathic medicine, based on A.T. Still's principles, allows osteopathic general practitioners to maintain their uniqueness in the medical community. The central approach is the same for all aspects of primary care from pediatrics to geriatrics. Offering residents that distinctive training should ensure the continued demand for osteopathic programs.

Ambulatory training sites are ideal settings for encouraging the ongoing use of osteopathic manipulative treatment (OMT). Residents can use OMT as the basis for the longitudinal care of patients with a large variety of visceral and somatic disorders. In addition, in the 2-year postinternship program, residents will have ample elective time to rotate with OMT specialists, developing in this way a skill in palpa- tory diagnosis and an expertise in a variety of treatment techniques.

\section{Research}

The findings of a 1987 survey $^{28}$ showed that only $0.2 \%$ of family physicians listed research as their primary professional work and that only $3.3 \%$ listed teaching as such. These figures reflect the minimal emphasis traditionally placed on research in family practice. The specialty, nonetheless, is not without research history. In a review of the roots of clinical investigation published in 1987, Booth ${ }^{29}$ discusses the works of MacKenzie on atrial fibrillation in the 19th century and progresses to studies currently being made at various institutions in such fields as preventive medicine.

One way to encourage academic research in the family practice specialty is through faculty development fellowships for family practice residents interested in academic careers. Two obstacles that would have to be overcome are the limited available time of the physician and limited funding. Even in academic institutions, family physicians often have very little time for non-patient-care duties..$^{30}$ With government health agencies focusing more and more on ambulatory and preventive medicine, family medicine departments should try to procure more research dollars than they have previously obtained.

The ACGP requires that each resident submit an annual paper as part of the basic requirements. This paper should serve as a vehicle for original research. Over 2 years, the resident has ample time to plan, perform, and evaluate a clinical research project.

\section{Difficulty issues}

Some fundamental aspects of residency training need to be reviewed periodically. These include items such as night call and work hours, competency testing and evaluation during the residency, and degrees of resident responsibility.

Night call has become a media issue. In 1987 , the long-running television show $60 \mathrm{Min}$ utes had a segment on the " 36 -hour shift," in which the commentators detailed the fatigue 
Table 4

Periodic Health Examination: Recommended Frequency, by Age

\begin{tabular}{|c|c|c|c|c|}
\hline Age & Annual & $\begin{array}{l}\text { Every } \\
2 \text { years }\end{array}$ & $\begin{array}{l}\text { Every } \\
5 \text { years }\end{array}$ & $\begin{array}{l}\text { Every } \\
10 \text { years }\end{array}$ \\
\hline All & $\begin{array}{l}\text { Ongoing health history } \\
\text { Weight, blood pressure: } \\
\text { teach and encourage } \\
\text { Physician examinations of } \\
\text { skin, breasts, } \\
\text { testicles (self-examination } \\
\text { monthly) } \\
\text { Counsel: nutrition, } \\
\text { exercise, tobacco } \\
\text { alcohol, seatbelts, } \\
\text { contraception }\end{array}$ & & & $\begin{array}{l}\text { Diphtheria- } \\
\text { tetanus } \\
\text { booster }\end{array}$ \\
\hline $20-39$ & $\begin{array}{l}\text { Pap smear } \\
\text { Gynecologic examination }\end{array}$ & & $\begin{array}{l}\text { Cholesterol } \\
\text { (if normal) }\end{array}$ & \\
\hline $40-49$ & $\begin{array}{l}\text { Breast and rectal } \\
\text { examinations } \\
\text { Pap smear } \\
\text { Gynecologic examination }\end{array}$ & & $\begin{array}{l}\text { Cholesterol } \\
\text { Audiometry }\end{array}$ & $\begin{array}{l}\text { Mammography } \\
\text { (once base- } \\
\text { line) }\end{array}$ \\
\hline $50-59$ & $\begin{array}{l}\text { Breast and rectal } \\
\text { examinations } \\
\text { Heme test of stools } \\
\text { Mammography } \\
\text { Pap smear } \\
\text { Gynecologic examination }\end{array}$ & & $\begin{array}{l}\text { Cholesterol } \\
\text { Audiometry } \\
\text { Sigmoidoscopy } \\
\text { (after two } \\
\text { normal results } \\
1 \text { yr apart) }\end{array}$ & \\
\hline$\geqslant 60$ & $\begin{array}{l}\text { Breast and rectal } \\
\quad \text { examinations } \\
\text { Heme test of stools } \\
\text { Mammography } \\
\text { Pap smear } \\
\text { Gynecologic examination }\end{array}$ & Audiometry & $\begin{array}{l}\text { Cholesterol } \\
\text { Sigmoidoscopy }\end{array}$ & \\
\hline
\end{tabular}

endured by a resident throughout a night on call and suggested that it had detrimental effects on resident attitudes and patient care. Within the medical community, many physician educators take issue with that conclusion, citing the long tradition of rigorous medical training that has led to the current healthy state of medical science.

Although work hours are a more critical issue for internship programs, this problem will have to be confronted by all residencies if legislators decide to regulate resident training, as has already been proposed in several states. In the PCOM program, general practice resi- dents currently share in-house call every 10 th to 12 th night. This is not excessive, compared with the requirements of some residency programs in other specialties. At PCOM, residents in general surgery, internal medicine, and pediatrics take in-house call more frequently. On the other hand, residents in several subspecialties take out-of-house call. In fact, residents in many other osteopathic general practice programs take call from home. At one institution, on-call time is negotiated by union agreement. The question of what is appropriate with regard to hours on call is certainly controversial. Regardless of which side they take, medi- 
cal educators are going to have to face the possibility that their hands may be forced by government intervention. This would necessitate the consideration of such alternatives as out-ofhouse call or the less desirable shift work.

Resident evaluation and testing is another issue facing residency trainers. In the 1-year program, all residents sat for a board-certification examination after completing the year. This examination was considered the final test of their progress as physicians. In a 2-year program, it would benefit both the residents and the trainers to have a way of objectively evaluating residents as they enter the last year. In 1976, Geyman and colleagues ${ }^{31}$ proposed an in-training examination for residents that is currently in use in allopathic family medicine programs. This type of test shows up weaknesses that can be overcome through the use of elective time and identifies strengths that a practice can be built on.

Family practice, by its nature, demands a breadth of knowledge from multiple disciplines. Thus, in training residents in general practice, rotations in such subspecialties as dermatology and orthopedics are relied on. In other fields, in contrast, residents are required to have in-depth knowledge in one discipline. Therefore, throughout their training, specialty residents will confront the same attending preceptors and will develop a stronger sense of responsibility toward them. The ambulatory care training site can serve to facilitate this important goal for the general practice resident. Ideally, general practice residents on subspecialty rotations should be practitioners rather than students, although often it is not practical for them to participate on an equal basis with the specialty residents. It is essential that good communication be maintained between the general practice trainer and both the resident and his or her subspecialty supervisor.

\section{Promoting osteopathic general practice}

From the days of A.T. Still to the present, the profession of osteopathic medicine has been built on primary care. In the 1960 s and 1970 s, the practice of medicine, dominated by allopathic physicians, became segmented, special- ized, and subspecialized, leaving the generalist outdated. Despite this development, osteopathic general practice has always been strong. While the allopathic community attempted to phase out the profession of family practice, the osteopathic medical community maintained its base in primary care. At present, many medical and government leaders are recognizing a shift in medical trends. ${ }^{32}$ They are recognizing the public need for family practice and the benefits of promoting it. As a group that has never lost sight of this need, we as osteopathic general practitioners are in a unique and favorable position to advance as providers of primary health care. To cultivate this advantage, we need to demonstrate and encourage the competent provision of general practice care.

The future of osteopathic general practice depends on our ability to develop and maintain the highest quality residency training and to attract osteopathic medical graduates to these residency programs. Some avenues that the profession can take to promote osteopathic general practice are as follows:

- Increase exposure of first- and second-year medical students to general practice. Courses in ambulatory care, physical diagnosis, preventive medicine, and geriatrics can be given by family practice departments and included in the students' early curriculum.

- Promote general practice within the medical community. General practitioners can seek leadership positions in hospital and academic administration and thereby improve the status of our profession.

- Educate the public about the role of osteopathic general practitioners as primary care providers and health promotion advocates.

- Become involved in government and public affairs that support general practice. Various legislative proposals now being considered could dramatically change reimbursement rules, such as the relative value scale, a plan to restructure Medicare schedules developed by Harvard public health specialists. General practice societies should actively lobby for this plan, since it has the potential to raise payments for providing primary care. If we lose osteopathic medical gradu- 
Table 5

Basic Requirements of Two-Year Postinternship Residency

\begin{tabular}{|c|c|}
\hline General practice & $\begin{array}{l}\text { Year } 1: 3 \text { half-days per week at } \\
\text { ambulatory training site } \\
\text { Year 2: More than } 3 \text { half-days per week }\end{array}$ \\
\hline Osteopathic principles and practice & $\begin{array}{l}\text { Taught at ambulatory training site in } \\
\text { longitudinal fashion }\end{array}$ \\
\hline Behavioral science & Longitudinal didactic and clinical training \\
\hline Nonclinical curricula & $\begin{array}{l}\text { Ethics, risk management, community services, etc; } \\
\text { taught similarly to behavioral science }\end{array}$ \\
\hline Geriatrics & $\begin{array}{l}\text { Ambulatory training site, hospital, nursing home, } \\
\text { home visits, etc, in longitudinal fashion }\end{array}$ \\
\hline Internal medicine & 4-month minimum; mix of hospital/ambulatory \\
\hline Surgery & $\begin{array}{l}\text { 2-month minimum; especially orthopedics, urology, } \\
\text { and otorhinolaryngology }\end{array}$ \\
\hline Obstetrics/gynecology & 3-month minimum; adapt to resident's goal \\
\hline Pediatrics & 3-month minimum \\
\hline Emergency medicine & 2-month minimum \\
\hline Elective & $\begin{array}{l}\text { Year 1: 2-month minimum } \\
\text { Year 2: 6-month minimum }\end{array}$ \\
\hline
\end{tabular}

ates to higher-paying procedure-based fields, the result will be a shortage of primary care providers, an outcome that is certainly not desired by government decisionmakers. Similarly, general practitioners must continue the effort to control medical liability costs.

- Advocate continued training in OMT in residency programs. Promote OMT, not only as an efficacious medical modality and as a potential means of increasing business in private practice, but as the basis of osteopathic medicine.

- Serve as positive role models to idealistic graduates by keeping abreast of the latest medical knowledge through continuing medical education and by maintaining high ethical standards in practice.

- Provide a residency program of the highest possible quality. Encourage capable and interested residents to pursue academic ca- reers. The 2-year postinternship program that is coming into effect promises to supply that level of training and to produce physicians who are exceptionally capable of managing the medical and psychosocial problems of today's practice (Table 5).

1. Basic Standards for Residency Training in General Practice American Osteopathic Association and American College of General Practioners in Osteopathic Medicine and Surgery Draft. Chicago, 1988.

2. Directory of Graduate Medicine Education Programs 19881989. Chicago, ACGME, AMA, 1988, p 123.

3. Yearbook and Directory of Osteopathic Physicians 1987 1988, ed 79. Chicago, American Osteopathic Association, 1987, p 519.

4. Ellsbury KE, Schneeweiss R, Montano DE, et al: Content of the model teaching unit ambulatory care training and continuity of care in six family practice residency programs. $J$ Fam Pract 1987;25:273-278.

5. Rogers J, Curtis P: The concept and measurement of continuity in primary care. Am J Public Health 1980;70:122-127.

6. Carey TS, Bennard B: Involvement of three types of precep- 
tors with residents in an ambulatory care clinic. $J$ Med Educ 1988;63:479-482.

7. Stern RS, Jennings M, Delbanco TL, et al: Graduate education in primary care: An economic analysis. $N$ Engl $J$ Med 1977;297:638-643.

8. Perkoff GT: Teaching clinical medicine in the ambulatory setting: An idea whose time may have finally come. $N \mathrm{Engl} \mathrm{J}$ Med 1986;314:27-31.

9. Nelson S: How much revenue does a physician bring in? Hospitals 1987;61(11):56.

10. Model Residency Training Program in General Practice. Chicago, American College of General Practitioners in Osteopathic Medicine and Surgery and American Osteopathic Association, 1988.

11. Ferentz KS, Sobal J, Colgan R: Hospital privileges for family practice: Patterns of recent residency graduates, residency director preceptors, and resident expectations. $J$ Fam Pract 1988;27:297-301.

12. Weiss BD: Family practice in hospitals. JAMA 1985;253:549.

13. Hainer BL, Lawler FH: Comparison of critical care provided by family physicians and general internists. JAMA 1988;260:354-358.

14. Kriebel SH, Pidds JD: Obstetric outcomes in a rural family practice: An eight year experience. J Fam Pract 1988;27(4):381377.

15. National Ambulatory Medicine Care Survey: 1985, Summary. US Department of Health and Human Service publication (PHS) 128.

16. Goodenough GK, Whitman N: Certificates of added qualification in geriatrics: The academic perspective. $J$ Fam Pract 1988;26:687-688.

17. Kuhn TS: The Essential Tension: Selected Studies in Scientific Tradition and Change. Chicago, University of Chicago Press, 1977.

18. Shapiro J: The maturing of family medicine: Challenges to behavioral science. J Fam Pract 1988;26:583-584.
19. Strain JJ, Pincus HA, Gise LH, et al: Mental health education in three primary care specialties. $J$ Med Educ 1986;61:958966.

20. Rosenberg EE, Steinvert YE: Psychosocial problems: What help do rural and urban patients want from their family physicians? Can Med Assoc J 1987;136:137-141.

21. Johnson SM, Kurtz ME: An innovative course on doctorpatient relationships: Preparation for interacting with patients. JAOA 1986;86:248-253.

22. Medical Practice Committee, American College of Physicians: Periodic health examination: A guide for designing individualized preventive health care in the asymptomatic patient. Ann Intern Med 1981;95:729-732.

23. Cheyney C, Ramsdell JW: Preventive health measures carried out by residents during new and follow up patient visits. $J$ Med Educ 1986;61:321-323.

24. Guidelines for the cancer related checkup: Recommendations and rationale. Cancer 1980;30:194-240.

25. Ravenholt RT: Addiction mortality in the United States 1980: Tobacco, alcohol, and other substances. Popular Dev Rev 1984;10:697-724.

26. Smoking and Health: A report of the Surgeon General. PHS, DHEW publication number (PHS) 79-50066. Government Printing Office, 1979.

27. DiFenza JR, Moser BE, Ocken JK: Smoking cessation counseling by family physicians. J Fam Pract 1988;26:377-385.

28. American Academy of Family Physicians: Facts About Family Practice. Kansas City, Kans, Burd \& Fletcher Co, 1987.

29. Booth CC: Research and the GP. Br Med J 1987;295:1614.

30. Perkoff G: The research environment in family practice. $J$ Fam Pract 1985;21:389-393.

31. Geyman JP, et al: An in-training examination for residents in family practice. J Fam Pract 1976;3:409.

32. Council on Long Range Planning and Development of the American Medical Association: The future of family practice. JAMA 1988;260:1272. 